\title{
Tunable Photochromism of Spirobenzopyran via Selective Metal Ion Coordination: An Efficient Visual and Ratioing Fluorescent Probe for Divalent Copper Ion
}

\author{
$\mathrm{Na} \mathrm{Shao}^{\dagger}$, JianYu Ji ${ }^{\dagger}$, Hao Wang ${ }^{\ddagger}$, Ying Zhang ${ }^{\dagger}$, RongHua Yang ${ }^{\dagger, *}$, WingHong Chan ${ }^{\ddagger, *}$ \\ ${ }^{\dagger}$ Beijing National Laboratory for Molecular Sciences, College of Chemistry and Molecular Engineering, \\ Peking University, Beijing 100871, China; \\ ${ }^{\ddagger}$ Department of Chemistry, Hong Kong Baptist University, Kowloon Tong, Hong Kong, China
}

E-mail: Yangrh@pku.edu.cn, Whchan@hkbu.edu.hk

Fax: +86-10-62751708 

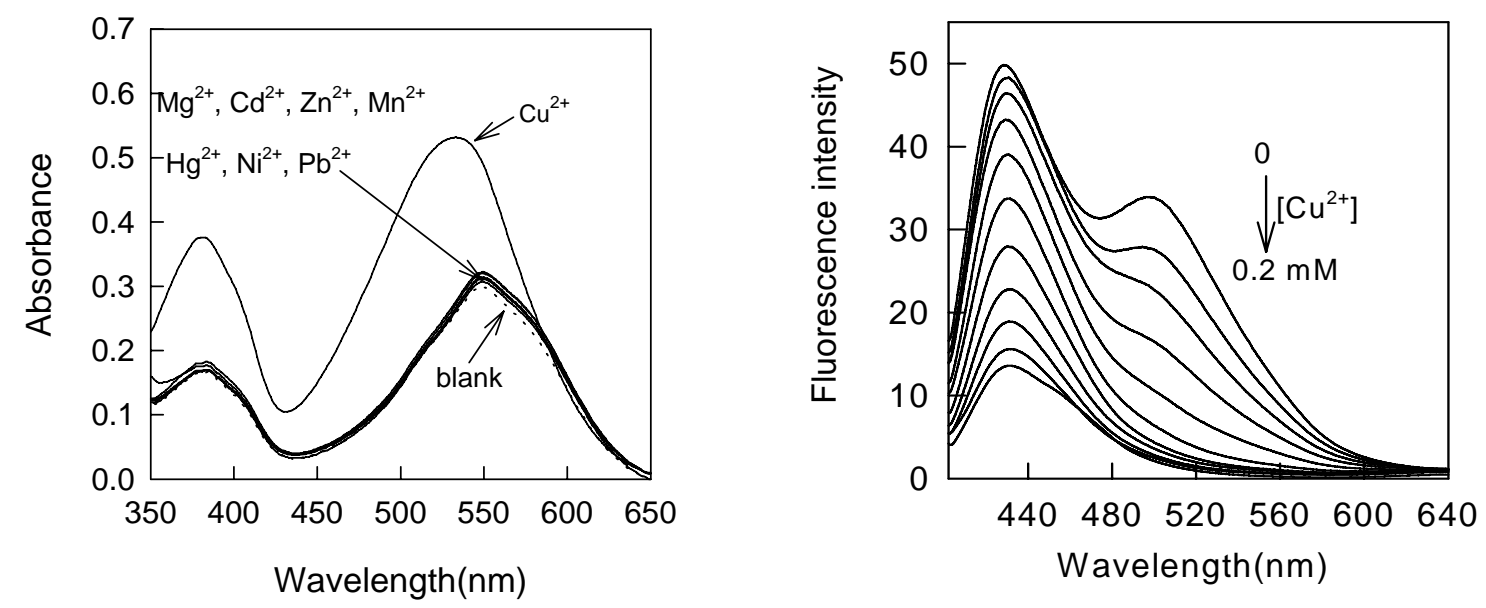

.Figure S1 left: UV-Vis absorption spectral changes of $2.0 \times 10^{-4} \mathrm{M} \mathbf{1}$ in the $50 \%$ ethanol-water $(\mathrm{v} / \mathrm{v})$ solution upon additions of $5.0 \times 10^{-5} \mathrm{M}$ of metal ions. The dashed line is the absorption curves without metal ion. Right: changes in fluorescence emission spectra $\left(\lambda_{\text {ex }}\right.$ $=402 \mathrm{~nm}$ ) of $2.0 \times 10^{-4} \mathrm{M} 1$ upon additions of different concentrations of $\mathrm{Cu}^{2+}$. The arrows indicate the signal changes as increases in the $\mathrm{Cu}^{2+}$ concentrations from 0 to $0.2 \mathrm{mM}$.
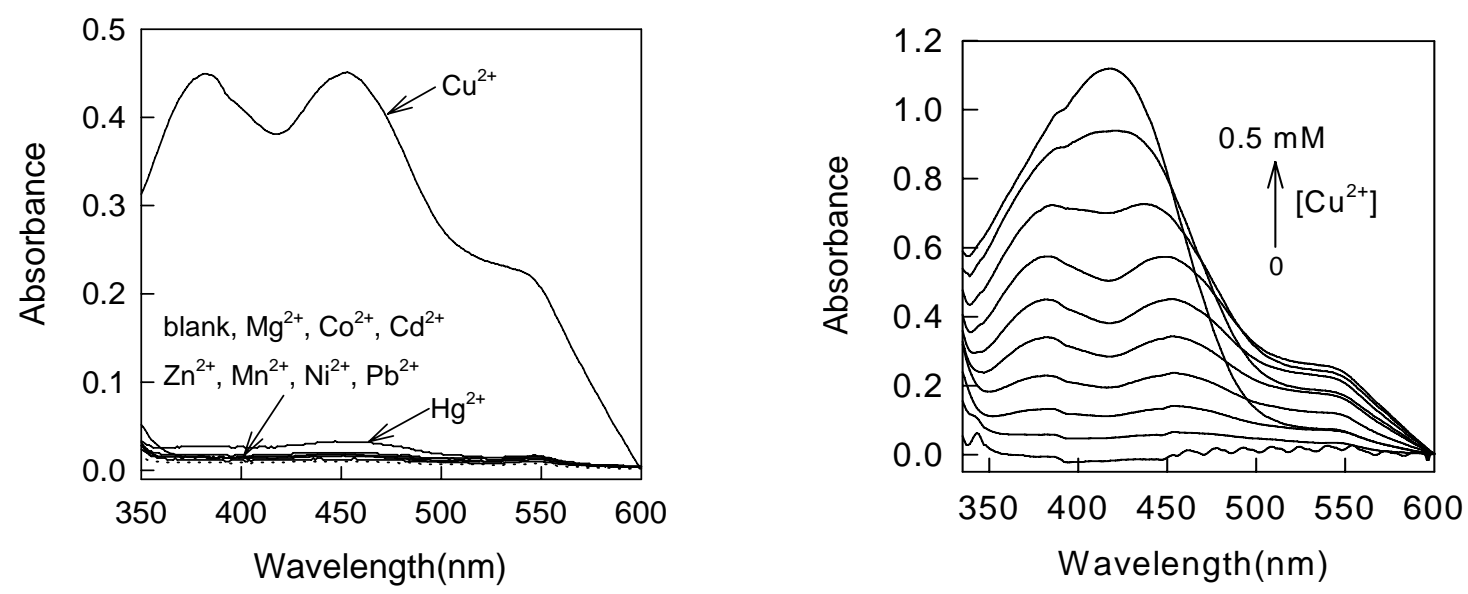

Figure S2 left: UV-Vis absorption spectral changes of $1.0 \times 10^{-4} \mathrm{M} 2$ upon additions of $5.0 \times$ $10^{-5} \mathrm{M}$ of metal ions. The dashed line is the absorption curves without metal ion. Right: UV-Vis absorption spectra of $1.0 \times 10^{-4} \mathrm{M} 2$ in the $50 \%$ ethanol-water $(\mathrm{v} / \mathrm{v})$ solution in the presence of different concentrations of $\mathrm{Cu}^{2+}$. The arrows indicate the signal changes as increases in the $\mathrm{Cu}^{2+}$ concentrations from 0 to $0.5 \mathrm{mM}$. 

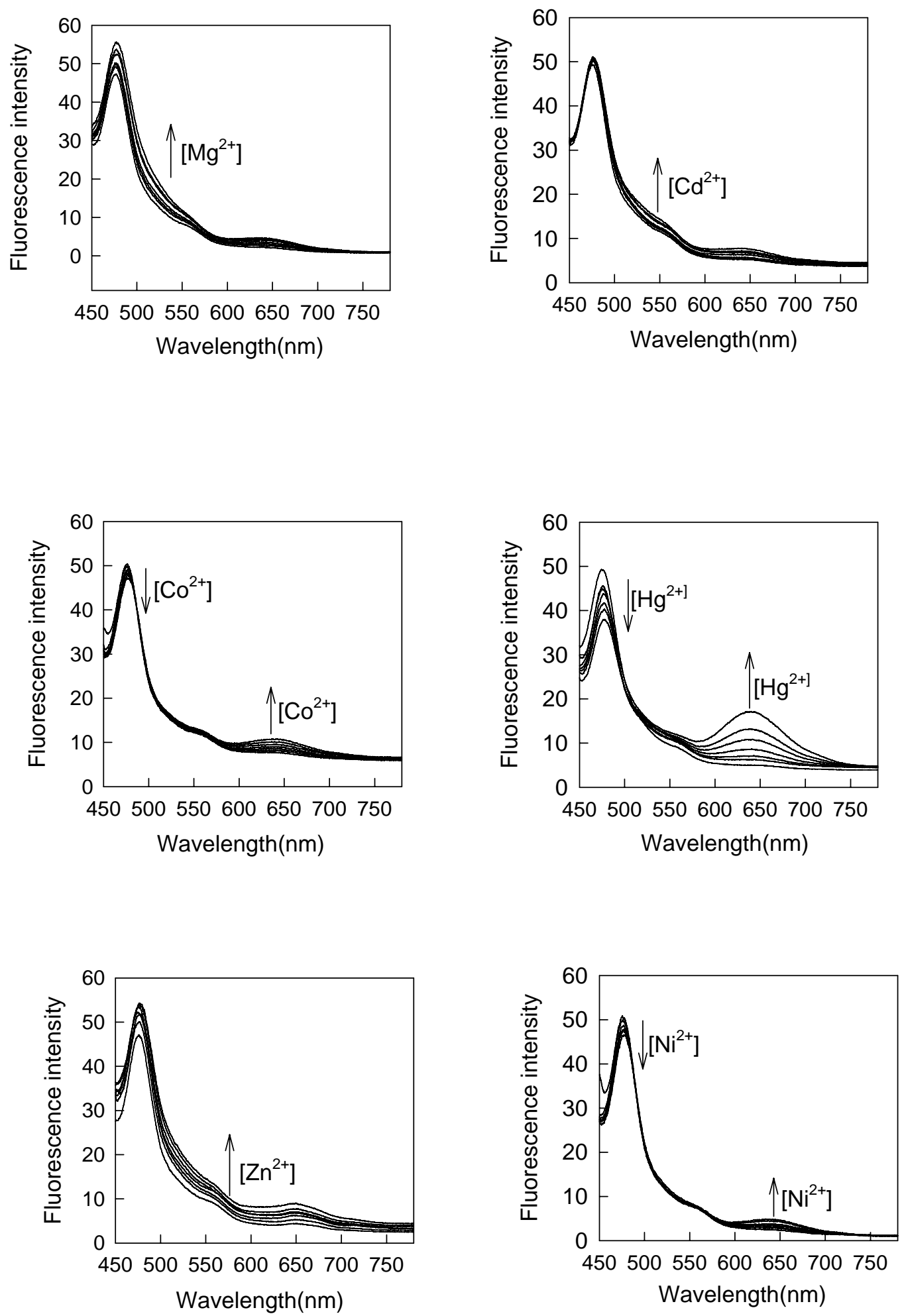



Figure S3 Fluorescence responses of 2 toward different metal ions in 50\% ethanol-water solution. The arrows indicate the signal changes as increasing in the concentration of metal $(0$, $5.0 \times 10^{-6}, 1.0 \times 10^{-5}, 2.0 \times 10^{-5}, 5.0 \times 10^{-5}, 1.0 \times 10^{-4}$ and $\left.2.0 \times 10^{-4} \mathrm{M}\right) .[2]=2.0 \times 10-4 \mathrm{M}$, $\lambda \mathrm{ex}=418 \mathrm{~nm}$.

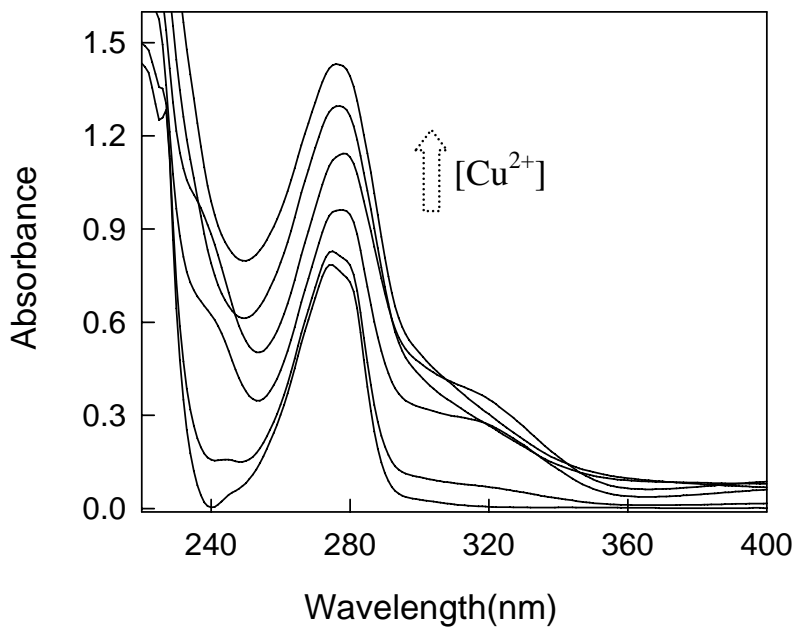

Figure S4 UV-Vis absorption spectra of $2.0 \times 10^{-4} \mathrm{M} 3$ in the $50 \%$ ethanol-water (v/v) solution in the presence of different concentrations of $\mathrm{Cu}^{2+}$. The arrows indicate the signal changes as increases in the $\mathrm{Cu}^{2+}$ concentrations $\left(0,1.0 \times 10^{-5}, 2.0 \times 10^{-5}, 5.0 \times 10^{-5}, 1.0 \times 10^{-4}\right.$, $\left.2.0 \times 10^{-4} \mathrm{M}\right)$. 


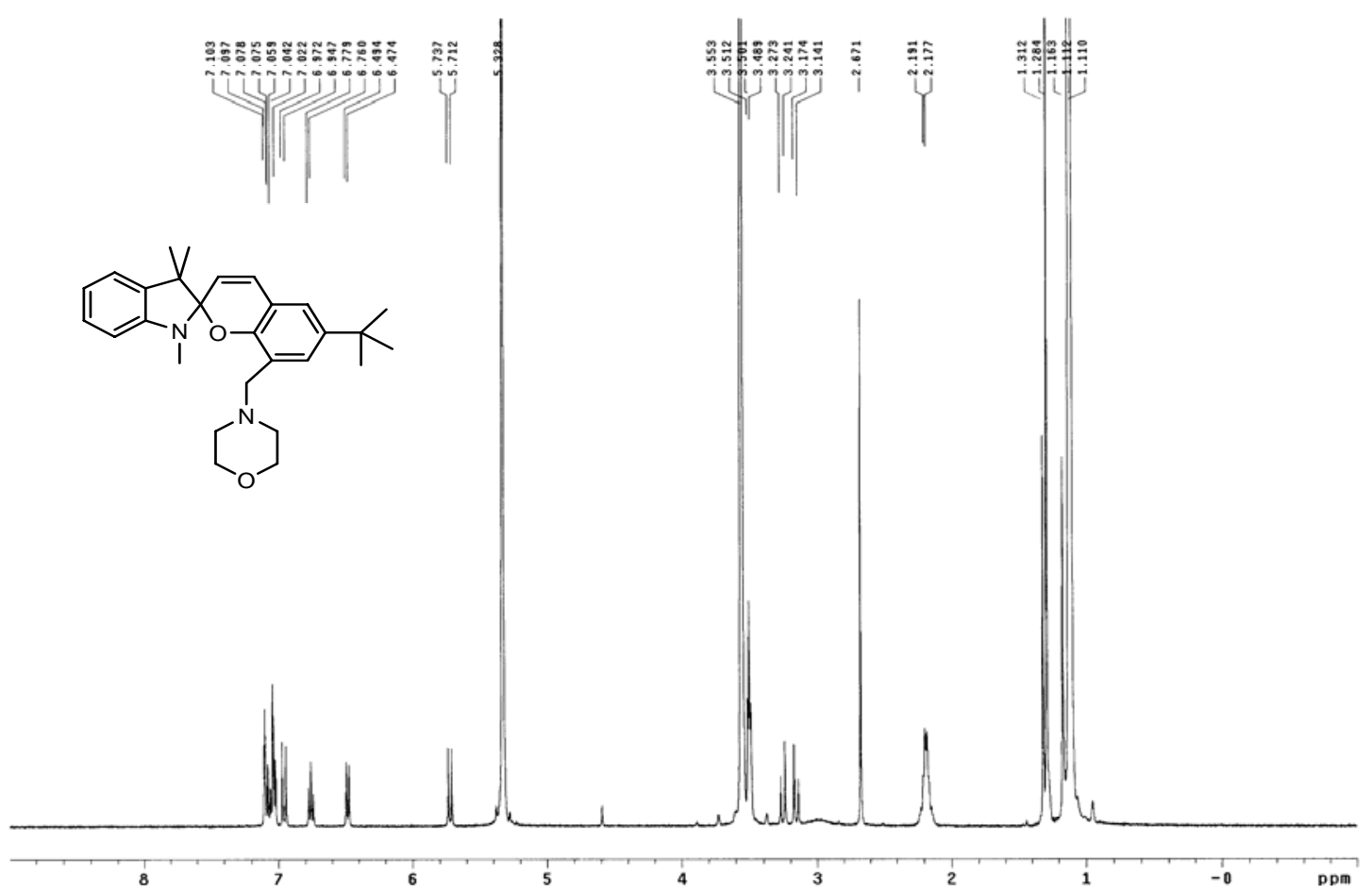

Figure S5 ${ }^{1} \mathrm{H}$ NMR of 2 in ethanol- $d_{6}$

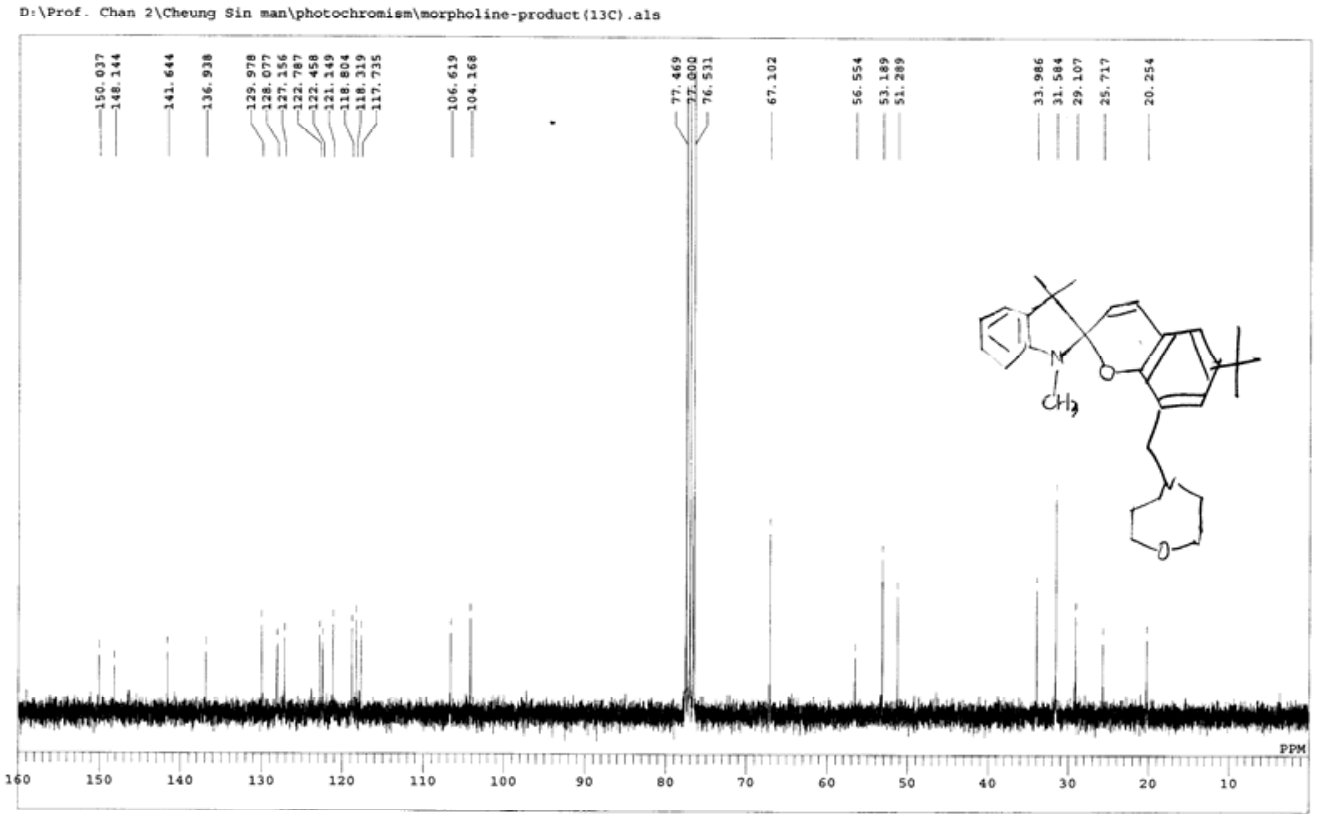

Figure S6 ${ }^{13} \mathrm{C}$ NMR of 2 in $\mathrm{CD}_{3} \mathrm{Cl}$ 


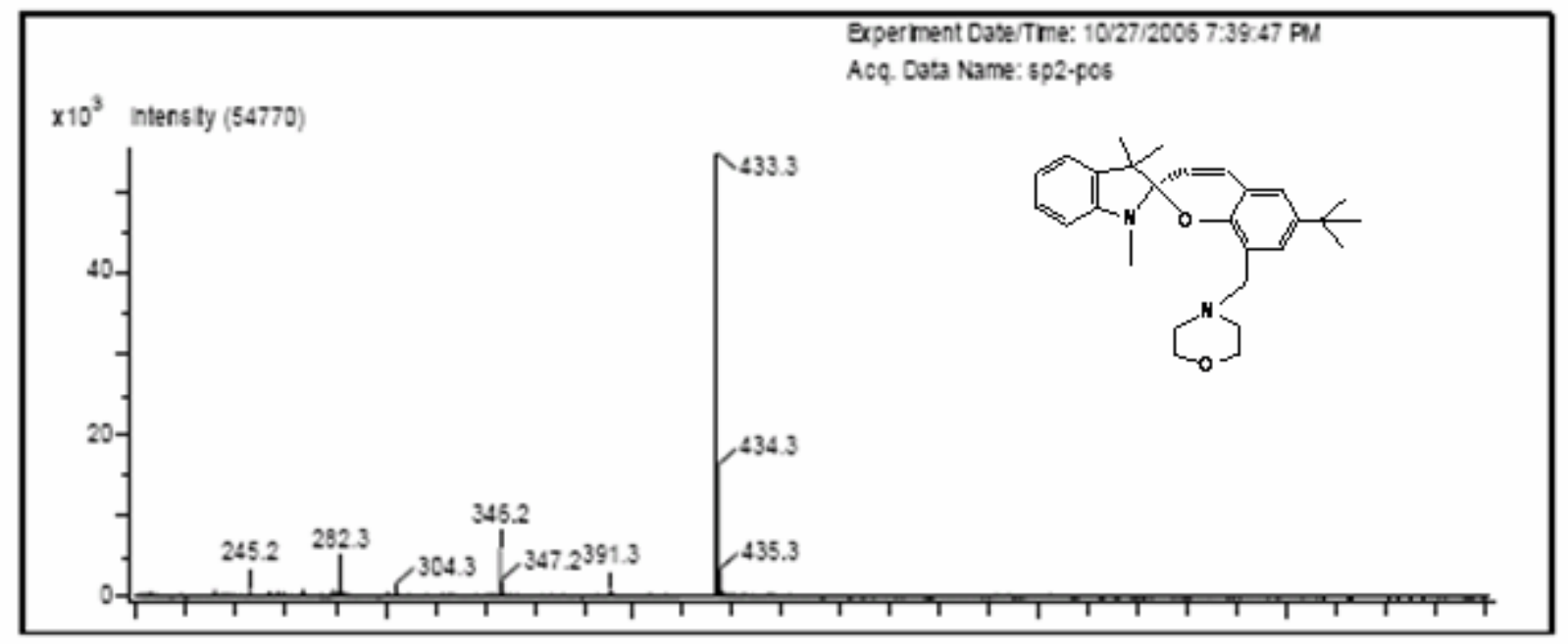

Figure S7 Cold-spray ionization time-of-flight mass spectrum of $\mathbf{2}$ in $\mathrm{CD}_{3} \mathrm{Cl}$. 




Figure S8 ${ }^{1} \mathrm{H}$ NMR spectra of 2 upon titrations with different concentrations of $\mathrm{CuCl}_{2}$ : (a), 0; (b), 0.3 equiv; (c), 0.6 equiv; and (d), 1.2 equiv. Measurements were performed in ethanol- $d_{6}$ at $25^{\circ} \mathrm{C}$. 


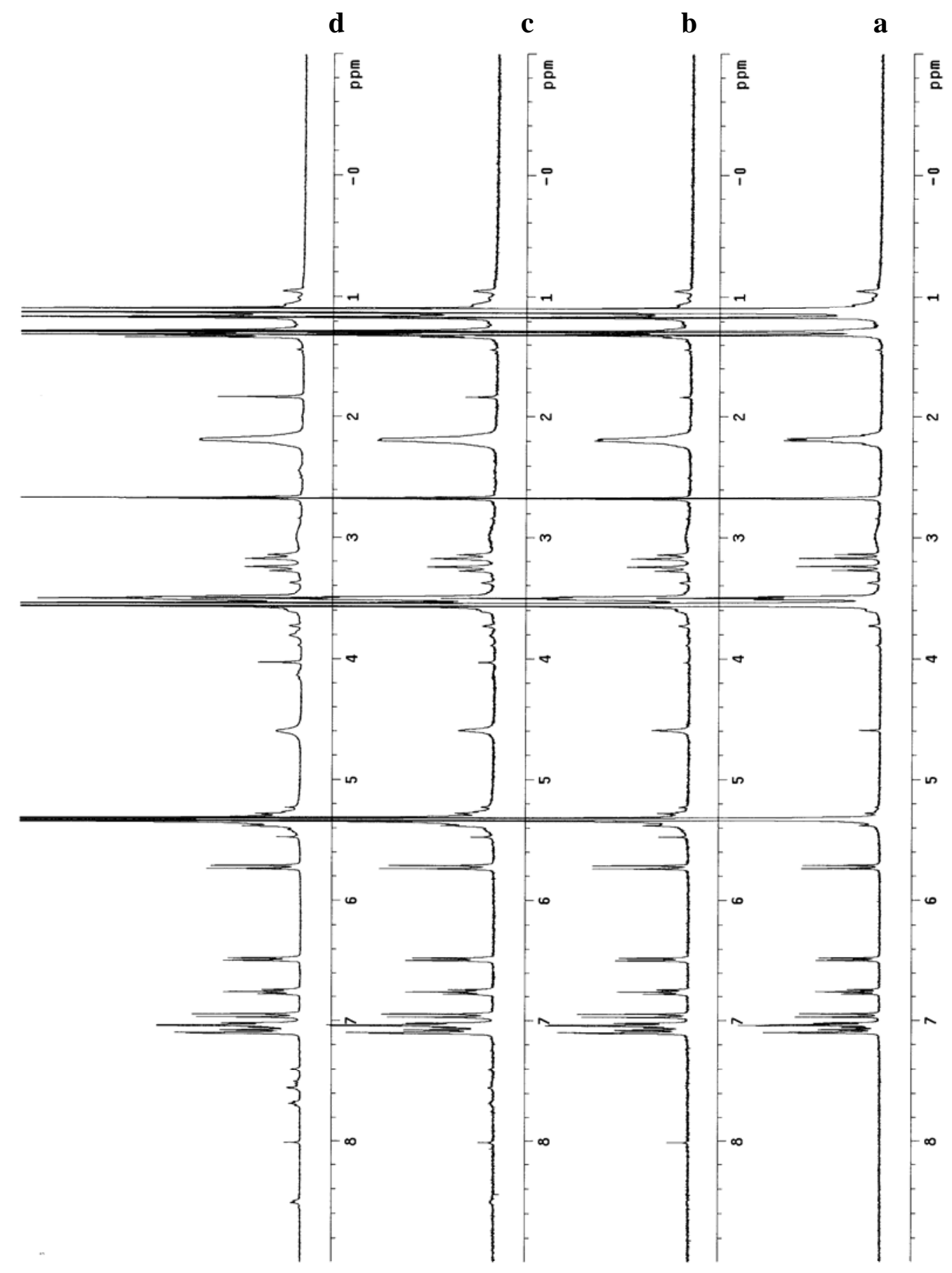

Figure S8 ${ }^{1} \mathrm{H}$ NMR spectra of 2 upon titrations with different concentrations of $\mathrm{ZnCl}_{2}$ : (a), 0; (b), 0.3 equiv; (c), 0.6 equiv; and (d), 1.2 equiv. Measurements were performed in ethanol- $d_{6}$ at $25^{\circ} \mathrm{C}$. 